\title{
Neuroprotective Effect of Pedalium murex Linn. Leaf against Lipopolysaccharide Induced Behavioural Disorders in Rats
}

\author{
Swaminathan Gomathi', Rajagopal Shanmuga Sundaram ${ }^{2 *}$, Vellaichamy Muthupandi Annapandian², Manickam \\ Vijayabaskaran ${ }^{1}$
}

\section{Swaminathan Gomathi ${ }^{1}$, Rajagopal Shanmuga Sundaram ${ }^{2 *}$, Vellaichamy Muthupandi Annapan- dian $^{2}$, Manickam Vijaya- baskaran ${ }^{1}$ \\ 'Department of Pharmaceutical Chemistry and JKK Nattraja College of Pharmacy, Komarapalayam, Namakkal, Tamil Nadu - 638183, INDIA. \\ 2Department of Pharmacology, Chemistry and JKK Nattraja College of Pharmacy, Komarapalayam, Namakkal, Tamil Nadu -638183, INDIA.}

\section{Correspondence}

Dr. R. Shanmuga Sundaram

M.Pharm., Ph.D., Professor and

Vice Principal, Department of

Pharmacology, JKK Nataraja College of

Pharmacy, Komarapalayam, Namakkal,

Tamil Nadu - 638183. INDIA

Phone: +91-9042864346 /

+91-9443284346

E-mail: malshan34@gmail.com

History

- Submission Date: 19-07-2017;

- Review completed: 11-08-2017;

- Accepted Date: 31-08-2017.

DOI : 10.5530/pj.2017.6.150

Article Available online

http://www.phcogj.com/v9/i6

\section{Copyright}

(C) 2017 Phcog.Net. This is an openaccess article distributed under the terms of the Creative Commons Attribution 4.0 International license.

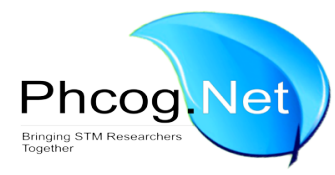

\begin{abstract}
Introduction: Effective treatment is necessary to minimize the neuronal damage and oxidative stress. Traditional medicines offer potent pharmacological activity with minimal side effects compared to synthetic drugs to treat such chronic disorders. There is no renowned remedy for arrest or rescuing infection or inflammation-induced brain damage. The present study was aimed to evaluate the neuroprotective effect of ethanol extract of Pedalium murex Linn. (EEPM) leaves against lipopolysaccharide (LPS)-induced endotoxemia. Methods: Neurodegeneration was induced in rats with a single intraperitoneal injection of LPS $(1 \mathrm{mg} / \mathrm{kg})$. The induced endotoxemia constantly linked with battery of behavioural tests viz., choice reaction time task (CRT), 8-arm radial maze (RAM) and water maze test (WMT). At the end of the study, rats were sacrificed, brain hippocampal region was removed and biochemical parameters were measured. Results: In WMT swimming length $(\mathrm{cm})$ was increased in LPS-treated rats when compared to control animals, the swimming length (EEPM; $400 \mathrm{mg} / \mathrm{kg}$ ) was found to be significant; in RAM, different doses of EEPM at 100, 200 and $400 \mathrm{mg} / \mathrm{kg}$ decreased the number of errors in entry $4.00 \pm 0.36,4.16 \pm 0.16$ and $3.33 \pm 2.79$ respectively when compared with control animals (2.66 \pm 0.21$)$. EEPM at $400 \mathrm{mg} / \mathrm{kg}$ showed significant activity, in CRT apparatus increased incorrect lever pressing was observed in LPS-treated rats when compared to control animals. Incorrect lever pressing was minimized by EEPM at $400 \mathrm{mg} / \mathrm{kg}$ $(43.5 \pm 2.40)$. Conclusions: Our results showed that EEPM is a hopeful aspirant for hindrance of infection and inflammation induced brain damage by LPS.
\end{abstract}

Key words: Behavioural studies, Learning, Memory, Neuroprotective, Oxidative stress, Pedalium murex.

\section{INTRODUCTION}

Activation of immune system in response to an infection or bacterial endotoxin lipopolysaccharide (LPS) produces profound neurophysiological, neuroendocrine and behavioral changes. To date, specific pharmacologic agents that can be used in the management of septic shock are lacking and yet a rather scanty number of potential therapeutic agents are under clinical trials. ${ }^{1}$ Endotoxic shock can be elicited by a systemic injection of LPS which induces the production and release of several cytokines. ${ }^{2}$ In response to these cytokines, several reactive oxygen species (ROS) are produced from cells such as neutrophils and other phagocytic cells, creating a status of oxidative stress. ${ }^{3}$ Thus, this type of stress may hypothetically support the assumption that LPSinduced cell injury would be retarded by modifying free radical metabolism with the aid of potent antioxidant pre-treatment from nature.

Certain reports have claimed that a few herbal extracts can act on the central nervous system, thereby enhancing the faculties of learning and memory. ${ }^{4}$ The chemicals derived from plants provide protection against a wide range of etiological factors. $^{5}$ Neuroprotective effect can be evaluated experimentally in LPS-induced rats with behavioral studies. In this present study, we have evaluated the medicinal herb Pedalium murex Linn. $(P$. murex) for its neuropretective effect against LPS-induced behavioural disorders. $P$. murex belongs to Pedaliaceae family and commonly known as "anainerinji". Leaves are a good source of natural antioxidant and widely consumed as vegetables due to its high nutritional value. ${ }^{6}$ Epidemiological studies have suggested positive associations between the consumption of phenolic-rich foods or beverages and the prevention of diseases. These effects have been attributed to antioxidant components such as plant phenolics, flavonoids and phenylpropanoids among others. ${ }^{7-8}$ Therefore, an attempt has been made to evaluate the neuroprotective effect of P. murex using LPS-induced endotoxemia in rats. 


\section{MATERIALS AND METHODS}

\section{Plant material}

P. murex was collected from Komarapalayam, Namakkal District, Tamilnadu, India. The plant was authenticated by Dr. G.V.S. Murthy, Scientist F, Botanical survey of India, Coimbatore, Tamilnadu (No.BSI/SRC/5/23/2012-13/Tech/1934). Then the leaves were isolated, cleaned and shade dried. Dried leaves are crushed to coarse powder and passed between pharmaceutical sieve number 40 and 80 . Materials which retained at sieve number 80 were collected and used for extraction.

\section{Preparation of crude extract}

Two-thousand grams of powdered leaf was extracted with n-hexane, chloroform, ethyl acetate and ethanol (90 \% v/v) continuously with soxhlet apparatus. Each extract was evaporated by the aid of rotary vacuum evaporator. The dried crude extract of individual solvent was weighed and the percentage yield was calculated. The dried crude extract was stored in a separate glass bottles at $-20^{\circ} \mathrm{C}$ until used.

\section{Preliminary phytochemical screening of P. murex}

Freshly prepared crude extracts of $P$. murex leaves were tested for the presence of alkaloids, flavonoids, phenolic components, steroids, saponins, terpenoids, glycosides, tannins, fixed oils, proteins and carbohydrates, as described in the textbook Harborne JB. ${ }^{9}$

\section{Assessment of in vitro antioxidant activity of P. murex leaves Total antioxidant activity}

Total antioxidant activity of $P$. murex extract was determined according to the thiocyanate method. ${ }^{10}$ Stock solution was prepared with $P$. murex extracts using distilled water. Further the final stock solution of $P$. murex extract was prepared with $12.5,25,50,100$ and $200 \mathrm{mcg} / \mathrm{ml}$. Potassium phosphate buffer $(2.5 \mathrm{ml} ; 0.04 \mathrm{M}, \mathrm{pH} 7.0)$, linoleic acid emulsion in potassium phosphate buffer $(2.5 \mathrm{ml} ; 0.04 \mathrm{M}, \mathrm{pH} 7.0)$ was added to the test solution and incubated at $37^{\circ} \mathrm{C}$. After incubation, $0.1 \mathrm{ml}$ of the incubated solution, $0.1 \mathrm{ml}$ of $\mathrm{FeCl}_{3}$ and $0.1 \mathrm{ml}$ thiocyanate were transferred to the ethanol $(4.7 \mathrm{ml})$ containing test tube. The mixture was again incubated for $5 \mathrm{~min}$. The absorbance was measured at $500 \mathrm{~nm}$ in a spectrophotometer against blank solution. The percentage inhibition of lipid peroxidation was calculated by the following equation:

$$
\text { Percent inhibition }=[\mathrm{A} 0-\mathrm{A} 1 / \mathrm{A} 0] \times 100
$$

Where A0 was the absorbance of the control reaction and A1 was the absorbance in the presence of the sample of $P$. murex.

\section{Hydroxyl radical scavenging activity}

Deoxyribose assay was used to determine the hydroxyl radical scavenging activity. The free radical damage imposed on the substrate was in the form of thiobarbituric reactive substance (TBARS) explained by Ohkawa et al. ${ }^{11}$ The reaction mixture containing $\mathrm{FeCl}_{3}(200 \mu \mathrm{mol})$, EDTA [1.04 $\mathrm{mmol}$ ], $\mathrm{H}_{2} \mathrm{O}_{2}(1 \mathrm{mmol})$ and 2-deoxy-D-ribose $(2.8 \mathrm{mmol})$ were mixed with or without extract at various concentration $(125-2000 \mu \mathrm{g} / \mathrm{ml})$ in $1 \mathrm{ml}$ final reaction volume made with potassium phosphate buffer $(20 \mathrm{mmol}, \mathrm{pH} 7.4)$ and incubated for $1 \mathrm{hr}$ at $37^{\circ} \mathrm{C}$. The mixture was heated at $95^{\circ} \mathrm{C}$ in water bath for $15 \mathrm{~min}$ followed by addition of $1 \mathrm{ml}$ each of TCA $(2.8 \%)$ and TBA ( $0.5 \%$ TBA in $0.025 \mathrm{M} \mathrm{NaOH}$ containing $0.02 \%$ BHA). Finally the reaction mixture was cooled in ice and centrifuged at $5000 \mathrm{rpm}$ for $15 \mathrm{~min}$. Absorbance of the supernatant liquid was measured at $532 \mathrm{~nm}$. Ascorbic acid was used as positive control.

\section{Pharmacological activity}

Animals

Sprague Dawley rats (100-150g) were used for the experiments. Animals were obtained from KMCH College of Pharmaceutical Sciences, Coimbatore, Tamil Nadu, India and maintained at standard housing conditions. A standard commercially available diet was provided with water ad libitum during the experiment. The animals were kept in clean and dry polycarbonate cages and maintained in a well-ventilated animal house with $12 \mathrm{~h}$ light/dark cycle. This study was approved by the institutional animal ethics committee (Reg. No KMCRET/Ph.D/08/2015-16).

\section{Acute oral toxicity study}

Acute toxicity study was performed according to OECD-guidelines 423 . Three animals of same sex were used in each group. Ethanol extract of P. murex (EEPM) was administered to each group at 5, 50, 300 and 2000 $\mathrm{mg} / \mathrm{kg}$ body weight respectively. The animals were fasted over-night before the administration of extract. Animals were observed regularly for 14 days for any signs and symptoms of toxicity.

\section{Experimental design}

Animals were randomly allotted into six groups with 6 animals in each group. EEPM was administered for a period of 30 days (p.o). Then neurodegeneration was induced with administration of intraperitoneal LPS $(1 \mathrm{mg} / \mathrm{kg})$ in normal saline on day 31 . Two hours after the administration of LPS, animals were subjected to behavioural tests and finally sacrificed and the brain was extracted for biochemical analysis.

Group I: Normal group. Animals received $0.1 \mathrm{ml}$ of normal saline orally for 30 days.

Group II: Disease control. Single dose of LPS (1mg/kg).

Group III: Standard group. Dexamethasone $(0.5 \mathrm{mg} / \mathrm{kg})$ for 30 days + LPS $(1 \mathrm{mg} / \mathrm{kg})$.

Group IV: Pre-treatment group. EEPM $100 \mathrm{mg} / \mathrm{kg}$ for 30 days + LPS $(1 \mathrm{mg} / \mathrm{kg})$

Group V: Pre-treatment group. EEPM $200 \mathrm{mg} / \mathrm{kg}$ for 30 days + LPS $(1 \mathrm{mg} / \mathrm{kg})$

Group VI: Pre-treatment group. EEPM $400 \mathrm{mg} / \mathrm{kg}$ for 30 days + LPS $(1 \mathrm{mg} / \mathrm{kg})$

\section{Behavioural tests for learning and memory}

Water maze test

The water maze consisted of a circular tank with $100 \mathrm{~cm}$ diameter and a wall of $20 \mathrm{~cm}$ above the water level. A circular platform was hidden $2 \mathrm{~cm}$ below the water level. The water was made opaque using titanium dioxide suspension and was kept at about $23^{\circ} \mathrm{C}$ during the experiment. Animals were trained for 5 consecutive days with 3 consecutive trials per day and an inter-trial interval of 6-10 min. Each trial started from one of four assigned polar positions with a different sequence each day. The swimming length of platform was measured till it finds the platform. ${ }^{12}$

\section{Radial-arm maze test ${ }^{13}$}

The apparatus was wooden elevated eight-arm radial maze with the arms extending from a central platform $26 \mathrm{~cm}$ in diameter. Each arm is $56 \mathrm{~cm}$ long, $5 \mathrm{~cm}$ wide and $2 \mathrm{~cm}$ height rails along the length of the arm. The maze was well illuminated and numerous cues were present. Food pellets (reward) were placed at the end of the arms. During the test, rats were fed once a day and their body weight maintained at $85 \%$ of their free feeding weight to motivate the rat to run the maze. Animals were trained on a daily basis in the maze to collect the food pellets for 24 days. The session was terminated after 8 choices and the rats had to obtain the maximum number of rewards with a minimum number of errors. 


\section{Choice reaction time task test ${ }^{14}$}

Rats were trained to press either of 2 levers with a continuous reinforcement schedule at a fixed ratio of 1:1. Trials began with differential reinforcement of another behaviour (DRO) period (random, 2-5 sec) during which the animals had to refrain from pressing either of the 2 levers. During the CRT period (maximum $10 \mathrm{sec}$ ), the time between sample presentation with the cue lamp on and pressing the correct lever was defined as the CRT and a food pellet reward will be provided through the pellet dispenser. With further lever-pressing responses, a house lamp was illuminated and intertribal interval (ITI; $20 \mathrm{sec}$ ) begun. One trial took approximately $30 \mathrm{sec}$, and each test session consisted of 30 trials. One session was performed every day for 30 days. The variables measured were the number of incorrect lever pressings during the DRO and ITI periods.

\section{Biochemical analysis}

At the end of study, animals were sacrificed and brain hippocampal region was carefully isolated, homogenized in a Potter-Elvehjem homogenizer with $0.1 \mathrm{M}$ phosphate buffer $(\mathrm{pH} 8)$ at temperature of $0^{\circ} \mathrm{C}$. The homogenate was then centrifuged at $10,000 \times \mathrm{g}$ for $5 \mathrm{~min}$ at $4^{\circ} \mathrm{C}$ and used for biochemical estimations like nitric oxide (NO) and Protein.

\section{Estimation of nitric oxide ${ }^{15}$}

The assay of nitric oxide content, in acid medium and in the presence of nitrite, formed nitrous acid diazotize sulphanilamide which was coupled with $\mathrm{N}$-(1-naphthyl) ethylenediamine. The resulting azo-dye had a bright reddish-purple colour, which was measured through spectrophotometry at $540 \mathrm{~nm}$.

\section{Estimation of protein}

Protein concentrations of the tissue homogenates was determined by the standard method of estimation explained by Lowry et al., using bovine serum albumin as the standard. ${ }^{16}$

\section{Statistical analysis}

The statistical analysis was carried out by one way analysis of variance (ANOVA) followed by Dunnet's test. The results values are expressed as mean \pm SEM observations from six animals in each group. $\mathrm{P}$ values ${ }^{\star} \mathrm{P}<0.05 ;{ }^{* *} \mathrm{P}<0.01 ;{ }^{* *} \mathrm{P}<0.001,{ }^{* * *} \mathrm{P}<0.0001$ were considered significant.

\section{RESULTS}

\section{Preliminary phytochemical screening}

Preliminary phytochemical screening revealed, $P$. murex leaves contains flavonoids, glycosides, tannins, carbohydrates, phenolic compounds, triterpenoids and saponins, fixed oil, gum, fat and mucilage. Ethanol extract showed the presence of maximum number of compounds. The results of preliminary phytochemical screening is summarized in table 1 .

\section{In vitro antioxidant studies}

Total antioxidant activity

The total antioxidant capacity of ethanol extract was found to be higher $(93.73 \%$ at $200 \mu \mathrm{g} / \mathrm{ml})$ when compared to other solvents used. The $\mathrm{IC}_{50}$ values of total antioxidant capacity of ascorbic acid, n-hexane extract, chloroform extract, ethyl acetate extract and ethanol extract was found to be $129.75 \mu \mathrm{g} / \mathrm{ml},>200 \mu \mathrm{g} / \mathrm{ml}, 65.41 \mu \mathrm{g} / \mathrm{ml}, 154.73 \mu \mathrm{g} / \mathrm{ml}$ and $12.74 \mu \mathrm{g} / \mathrm{ml}$ respectively. Amongst, ethanol and chloroform exhibited significant dose dependent antioxidant activity.

\section{Hydroxyl radical scavenging activity}

Hydroxyl radical scavenging activities of extracts of P.murex leaves were calculated using the standard curve of Gallic acid. All the four extracts, chloroform and ethanol extracts exhibited significant dose dependent hydroxyl radical scavenging activity. The IC50 values of gallic acid, chloroform extract and ethanol extract was found to be $23.92 \mu \mathrm{g} / \mathrm{ml}$, $124.0 \mu \mathrm{g} / \mathrm{ml}$ and $155.40 \mu \mathrm{g} / \mathrm{ml}$ respectively. EEPM showed a dose dependent free radical scavenging activity (Figure $1 \& 2$ ).

\section{Pharmacological activity \\ Acute toxicity study}

An acute toxicity study of EEPM did not produce any mortality of animals at the dose of $2000 \mathrm{mg} \mathrm{kg}-1$ body weight. Hence, doses of $100 \mathrm{mg} \mathrm{kg}-1,200 \mathrm{mg} \mathrm{kg}-1$, and 400 mg kg-1 were selected for investigating neuropreventive activity.

\section{Behavioural tests for learning and memory Water maze test}

Swimming length $(\mathrm{cm})$ was significantly increased in LPS-treated rats when compared to control animals. Administration of EEPM decreased the swimming length in treated animals. The effect of EEPM was profound

Table 1: Preliminary phytochemical screening of $P$. murex leaf extracts

\begin{tabular}{rccccc}
\hline Sr. No. & Chemical Test & n-hexane & Chloroform & Ethyl acetate & Ethanol \\
\hline 1. & Alkaloids & - & - & + & - \\
2. & Carbohydrates & - & - & + & - \\
3. & Glycosides & - & + & - & + \\
4. & Phytosterol & - & - & - & - \\
5. & Fixed oils and Fats & + & - & - & - \\
6. & Tannins & - & + & - & - \\
7. & Phenols & - & + & - & + \\
8. & Proteins & - & - & + & - \\
9. & Gums and Mucilages & + & - & - & - \\
10. & Flavonoids & - & - & - & + \\
11. & Terpenoids & - & - & - & + \\
12. & Steroids & + & - & - & - \\
13. & Saponins & - & - & + & + \\
\hline
\end{tabular}

+ Present; -Absent. 


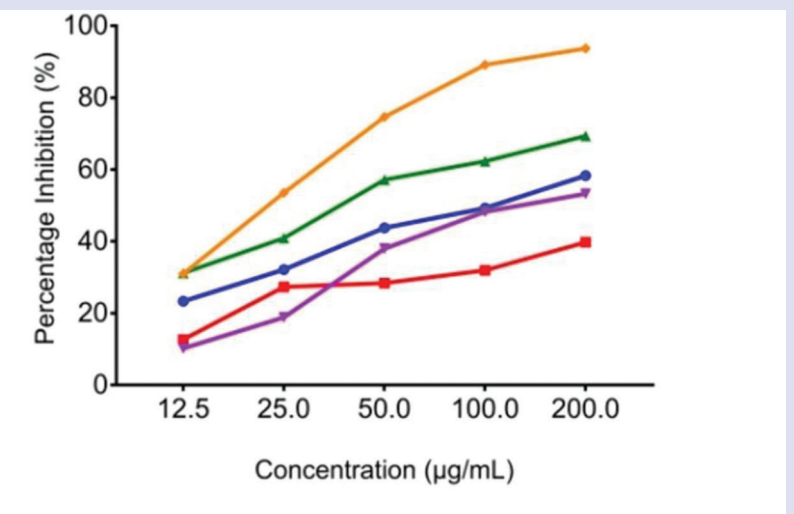

Standard - n-hexane $=$ Chloroform $\div$ Ethyl acetate - Ethanol

Figure 1: Total antioxidant activity of $P$. murex leaf

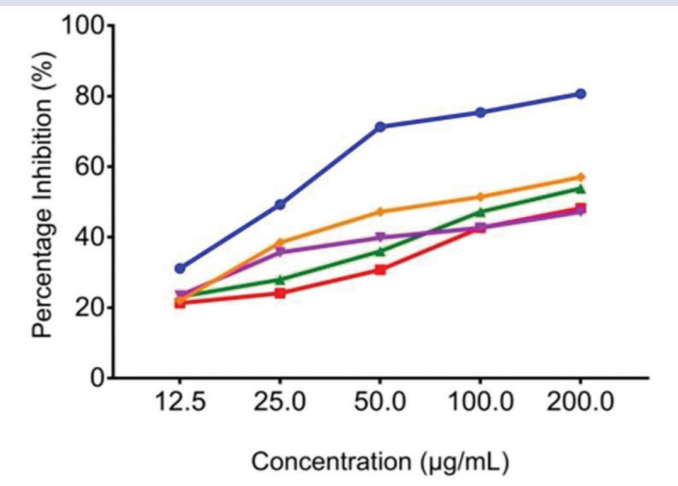

Standard $-\mathrm{n}$-Hexane $=$ Chloroform - Ethyl acetate - Ethanol

Figure 2: Hydroxyl radical scavenging activity of $P$. murex leaf

Table 2: Effect of EEPM on LPS-induced rats by water maze test

\begin{tabular}{ccc}
\hline Groups & Treatment & Swimming Length $(\mathrm{cm})$ \\
\hline I & Control & $23.00 \pm 0.93$ \\
II & LPS $(1 \mathrm{mg} / \mathrm{kg})$ & $42.17 \pm 1.13^{* * * *}$ \\
III & Dexamethasone $(0.5 \mathrm{mg} / \mathrm{kg})$ & $29.17 \pm 0.70^{* * *}$ \\
IV & EEPM $100 \mathrm{mg} / \mathrm{kg}$ & $43.50 \pm 3.21$ \\
V & EEPM $200 \mathrm{mg} / \mathrm{kg}$ & $37.17 \pm 2.41$ \\
VI & EEPM 400 $\mathrm{mg} / \mathrm{kg}$ & $34.50 \pm 1.97^{*}$ \\
\hline
\end{tabular}

Values are expressed as mean \pm SEM. Observations from six animals in each group. One-way ANOVA followed by Dennett's test was performed. Group II was compared with group I. Group III, IV, V and VI was compared with group II. ${ }^{\star} \mathrm{P}<0.05$; ${ }^{* *} \mathrm{P}<0.01 ;{ }^{* *} \mathrm{P}<0.00 ;{ }^{* * *} \mathrm{P}<0.0001$.

in $400 \mathrm{mg} / \mathrm{kg}$, which is statistically significant compared to control group (table 2).

\section{Radial-arm maze test}

LPS-treated group showed significant number of errors in entry when compared to control animals. Administration of different doses of EEPM at 100,200 and $400 \mathrm{mg} / \mathrm{kg}$ decreased the number of errors in entry
Table 3: Effect of EEPM on LPS-induced rats by 8-arm radial maze test

\begin{tabular}{ccc}
\hline Groups & Treatment & Number of errors \\
\hline I & Control & $2.66 \pm 0.21$ \\
II & LPS $(1 \mathrm{mg} / \mathrm{kg})$ & $5.00 \pm 0.51^{* * * *}$ \\
III & Dexamethasone $(0.5 \mathrm{mg} / \mathrm{kg})$ & $3.16 \pm 0.30^{* *}$ \\
IV & EEPM $100 \mathrm{mg} / \mathrm{kg}$ & $4.00 \pm 0.36$ \\
V & EEPM $200 \mathrm{mg} / \mathrm{kg}$ & $4.16 \pm 0.16$ \\
VI & EEPM $400 \mathrm{mg} / \mathrm{kg}$ & $3.33 \pm 2.79^{* *}$ \\
\hline
\end{tabular}

Values are expressed as mean \pm SEM. Observations from six animals in each group. One-way ANOVA followed by Dennett's test was performed. Group II was compared with group I. Group III, IV, V and VI was compared with group II. ${ }^{\star} \mathrm{P}<0.05$; ${ }^{* *} \mathrm{P}<0.01 ;{ }^{* * *} \mathrm{P}<0.00 ;{ }^{* * *} \mathrm{P}<0.0001$

Table 4: Effect of EEPM on LPS-treated rats by choice reaction time (CRT) task

\begin{tabular}{ccc}
\hline Groups & Treatment & $\begin{array}{c}\text { No of incorrect lever } \\
\text { pressing }\end{array}$ \\
\hline I & Control & $32.33 \pm 3.28$ \\
II & LPS $(1 \mathrm{mg} / \mathrm{kg})$ & $70.67 \pm 2.27^{* * * *}$ \\
III & Dexamethasone $(0.5 \mathrm{mg} / \mathrm{kg})$ & $39.17 \pm 2.46^{* * * *}$ \\
IV & EEPM 100mg/kg & $56.83 \pm 1.13^{* * *}$ \\
V & EEPM 200mg/kg & $63.17 \pm 1.42$ \\
VI & EEPM 400mg/kg & $43.50 \pm 2.40^{* * * *}$ \\
\hline
\end{tabular}

Values are expressed as mean \pm SEM. Observations from six animals in each group. One-way ANOVA followed by Dennett's test was performed. Group II was compared with group I. Group III, IV, V and VI was compared with group II. ${ }^{*} \mathrm{P}<0.05$; ${ }^{* *} \mathrm{P}<0.01 ;{ }^{* *} \mathrm{P}<0.00 ;{ }^{* * *} \mathrm{P}<0.0001$.

Table 5: Effect of EEPM on the rat brain antioxidant system in LPS-treated rats

\begin{tabular}{ccc}
\hline Groups & $\begin{array}{c}\text { Nitric oxide } \\
(\mu \mathrm{mol} / \mathrm{g} \text { tissue })\end{array}$ & Total proteins $(\mathrm{g} / \mathrm{dl})$ \\
\hline Control & $0.68 \pm 0.16$ & $1.46 \pm 0.03$ \\
LPS & $4.87 \pm 0.10^{*+*}$ & $1.04 \pm 0.10^{*+*}$ \\
Dexamethasone & $1.43 \pm 0.09^{* * *}$ & $1.35 \pm 0.17^{* * *}$ \\
EEPM 100mg/Kg & $2.90 \pm 0.13$ & $1.21 \pm 0.02$ \\
EEPM $200 \mathrm{mg} / \mathrm{Kg}$ & $2.67 \pm 0.82^{* * *}$ & $1.28 \pm 0.09^{* * *}$ \\
EEPM $400 \mathrm{mg} / \mathrm{Kg}$ & $1.98 \pm 0.55^{*+*}$ & $1.34 \pm 0.12^{* * *}$ \\
\hline
\end{tabular}

Values are expressed as mean \pm SEM. Observations from six animals in each group. One-way ANOVA followed by Dennett's test was performed. Group II was compared with group I. Group III, IV, V and VI was compared with group II. ${ }^{\star} \mathrm{P}<0.05$; ${ }^{* *} \mathrm{P}<0.01 ;{ }^{* *} \mathrm{P}<0.00 ;{ }^{* * *} \mathrm{P}<0.0001$.

$4.00 \pm 0.36,4.16 \pm 0.16$ and $3.33 \pm 2.79$ respectively when compared with control animals $(2.66 \pm 0.21)$, (Table 3$)$

\section{Choice reaction time task test}

Increased incorrect lever pressing was observed in LPS-treated rats when compared to control animals in a CRT apparatus. Incorrect lever pressing was minimized by when EEPM was administered at 100, 200 and $400 \mathrm{mg} / \mathrm{kg}(56.83 \pm 1.13,63.17 \pm 1.42$, and $43.50 \pm 2.40$ respectively). EEPM at $400 \mathrm{mg} / \mathrm{kg}$ showed significant activity when compared with LPS-treated group $(70.67 \pm 2.27)$, (Table 4). 


\section{Biochemical estimation}

Nitric oxide levels were found to be elevated and the protein level decreased in LPS-treated rats when compared to control rats, due to neuroinflammation and oxidative stress. The perturbations in the levels of $\mathrm{NO}$ and protein were found to be almost normalized following treatment with different doses of EEPM when compared with control group (Table 5).

\section{DISCUSSION}

Learning and memory is one of the most intensively studied subjects in the field of neuroscience. ${ }^{17}$ Learning is the process of acquisition of information and skills, while subsequent retention. ${ }^{18}$ Currently available psychoactive drugs, mainly anxiolytics and anti-depressants do not often properly meet the therapeutic demands of patients suffering co morbid psychiatric conditions, and the drawbacks of such drugs in terms of unwanted side effects, incredible benefits and moderate costs. ${ }^{19} \mathrm{~A}$ variety of herbal extracts and their components have been demonstrated to exert neuroprotective effects associated with antioxidant activities, ${ }^{20,21}$ either by directly stimulating antioxidant response genes or by potentiating the bodies' own natural antioxidant defense systems. P.murex shares many of the medicinal properties with other 'rasayans' and its neuroprotective effect in different neurodegenerative models is debatable and yet to be established. In this study we had evaluated the herb P. murex leaf for LPS-induced endotoxemia along with antioxidant potential using ethanol solvent extract. The plant $P$. murex is a well-known herbal medicinal plant used in the Indian medicines for treating several diseases.

\section{Phytochemical studies}

Preliminary phytochemical studies were carried out on n-hexane, chloroform, ethyl acetate, ethanol extracts of P.murex leaves. The results showed the presence of flavonoids, alkaloids, glycosides, carbohydrates, terpenoids, tannins, phenolic compounds in P.murex leaves. Ethanol extract showed the presence of maximum number of compounds.

The total antioxidant capacity of ethanol extract was found to be higher $(93.73 \%$ at $200 \mu \mathrm{g} / \mathrm{ml}$ ) when compared to other solvents used. The total antioxidant capacities of different solvent extracts of leaves of $P$. murex at various concentrations $(12.5-200 \mu \mathrm{g} / \mathrm{ml})$ were in the following order: ethanol $>$ chloroform $>$ ethyl acetate $>$ n-hexane. The hydroxyl radical activity of extracts of leaves of $P$. murex in the order of antioxidant potency of $P$. murex leaf extracts in our study was found to be, chloroform $>$ ethanol $>$ n-hexane.

\section{Pharmacological studies}

Mazes are traditionally used to evaluate spatial learning and memory. Spatial memory is a form of short term memory utilizing neuro circuitry that provides temporary storage and manipulation of information necessary for complex cognitive tasks such as language comprehension, learning and reasoning. ${ }^{22}$ Its impairment is analogous to memory disorder in Alzheimer's dementia. ${ }^{23}$ EEPM pre-treatment significantly reduced escape latency in morris water maze performance, facilitating learning and memory processes integral to spatial navigation. The reduction in distance travelled with lower doses of EEPM does not meet the criteria of a classic nootropic agent as the effect disappeared at higher doses. ${ }^{24}$ However, distance travelled can be reduced either via improved cognition or a change in swimming behaviour influenced by serotonergic transmission. ${ }^{25}$ In the present investigation, a significant nootropic effect was observed with respect to escape latency with all doses of EEPM. We believe that at higher doses, flavonoid components in EEPM may have exerted an inhibitory effect on swimming behaviour via serotonergic mechanisms, ${ }^{26}$ and will explore this in future work.
In behavioral neuroscience trial, radial 8 arm-maze (RAM) task is widely used. ${ }^{27,}{ }^{28}$ These RAM tests are useful in evaluating the effect of drugs, stress and various other environmental factors on learning and memory. Working memory and reference memory are the two variables that report the physiological status of the brain. ${ }^{29}$ Thus, LPS-treated rats with the EEPM $(100,200$ and $400 \mathrm{mg} / \mathrm{kg})$ exhibited an improvement of working memory as compared to LPS alone-treated rats in radial arm-maze task. The choice reaction time task represents the first step of cognition and memory and is related to attention and immediate memory retention ability. ${ }^{30}$ The incorrect lever pressing was more in LPS-treated rats. Attention capacity would be recovered by EEPM pre-treatment rats (100, 200 and $400 \mathrm{mg} / \mathrm{kg})$.

\section{In vivo antioxidant activity}

The NO level was increased protein level was decreased in LPS-treated rats were significantly reversed by EEPM pre-treatment rats. Oxidative changes to proteins due to NO can lead to diverse functional consequences such as inhibition of enzymatic activities, proteolysis and altered immunogenicity. ${ }^{31}$

In our findings, EEPM showed significant results in preliminary phytochemical studies and in vitro free radical scavenging activity prompted us to select the ethanol extract for pharmacological screening. Behavioural tests for learning and memory, biochemical estimation results indicated that the endotoxin, LPS, leads to minimal attention capacity, decreased the short term memories in rats which were found to be reversed by EEPM when compared to control treated groups. In this study, a different dose of EEPM ceases the high level of NO and recovers the level of protein in hippocampus region of rat brain.

\section{CONCLUSION}

Our study results showed that attention and short-term working memory of the animals were severely impaired by LPS. Treatment with EEPM significantly improved the impairment. EEPM is a potential agent for LPS-induced brain damage which may be attributed to the presence of potent antioxidants in $P$. murex leaves. Our study warrants for further research, isolation and characterization of potent compound responsible for the neuroprotective effect.

\section{ACKNOWLEDGEMENT}

The authors acknowledge the Principal, KMCH College of Pharmacy, and Coimbatore, India for all supports during the study and permission granted to carry out the pharmacological work at their premises.

\section{FINANCIAL SUPPORT AND SPONSORSHIP}

Nil.

\section{CONFLICTS OF INTEREST}

All authors have no conflict of interest.

\section{ABBREVIATIONS USED}

EEPM - ethanol extract of Pedalium murex; LPS - lipopolysaccharide; CRT - choice by reaction time; P. murex - Pedalium murex.

\section{REFERENCES}

1. Gallily R, Yamin A, Waksmann Y, Ovadia H, Weidenfeld J, Bar-Joseph, et al Protection against septic shock and suppression of TNF $\alpha$ and NO production by dexanabinol (HU-211), a non-psychotropic cannabinoid. J Pharmacology Exp Ther. 1997;283(2):918-24

2. Morrison D, Ryan JL. Endotoxins and disease mechanism. Annu Rev Med 1987;38(1):417- 32. 
3. Sugino K, Dhi K, Yamada K, Kawill Beaki T. The role of lipid peroxidation in endotoxin-induced hepatic damage and the protective effect of antioxidants. Surgery. 1987; 101(6):746-52.

4. Ahmed F, Chandra J N, Manjunath S. Acetylcholine and memory-enhancing activity of Ficus racemosa bark. Phcog Res. 2011;3(4):246-9.

5. Sharma A, Shetty M, Parida A, Adiga S, Kamath S, Sowjanya. Effect of ethanolic extract of Acacia auriculiformis leaves on learning and memory in rats. Phcog Res. 2014;6(3):246-50

6. Sulakhiya K, Patel VK, Saxena R, Dashore J, Srivastava AK, Rathore M. Effect of Beta vulgaris Linn. leaves extract on anxiety- and depressive-like behavior and oxidative stress in mice after acute restraint stress. Phcog Res. 2016;8(1):1-7.

7. Subramanian SS, Nair AGR. Flavonoids of the leaves of Pedalium murex. Phytochemistry. 1972;11(1):464-5

8. Bhakuni RS, Shukla YN, Thakur RS. Flavonoids and other constituents from Pedalium murex. Phytochemistry. 1992;31(8):2917-8.

9. Harborne JB. Phytochemical Method. A Guide to modern techniques of plant Analysis, $3^{\text {rd }}$ edition, Springer (India) Pvt. Ltd, New Delhi; 2005.p.5-16,22.

10. Mitsuda H, Yasumoto K, Iwami K. Antioxidative action of indole compounds during the autoxidation of linoleic acid. Nihon Eiyo-Shokuryo Gakkai-Shi. 1966;19(3):210-4.

11. Ohkawa $\mathrm{H}$, Ohishi $N$, Yagi K. Assay for lipid peroxides in animal tissues by thiobarbituric acid reaction. Anal Biochemistry. 1979;95(2):351-8.

12. Olton DS, Samuelson RJ. Remembrance of places passed: spatial memory in rats. J Exp Psychol Ann Behav Proc. 1976;2(2):97-116.

13. Morris R. Developments of a water-maze procedure for studying spatial learning in the rat. J Neuroscience Meth. 1984;11:47-60.

14. Ikeda TMD, Mishima K, Aoo N, Liu AX, Egashira N, Katsunori IB, et al. Dexamethasone prevents long-lasting learning impairment following a combination of lipopolysaccharide and hypoxia-ischemia in neonatal rats. Am J Obsts \& Gynecol. 2005;192(3):719-26.

15. Green LC, Wagner DA, Glogowski J, Skipper PL, Wishnok JK, Tannenbaum $\mathrm{SR}$. Analysis of nitrate, nitrite and $15 \mathrm{~N}$ in biological fluids. Anal Biochem. 1982;126(1):131-8.

16. Lowry $\mathrm{OH}$, Rosebrough NJ, Farr AL, Randall RJ. Protein measurement with the Fooling phenol reagent. J Biol Chem. 1951;193(1):265-75.

17. Sumit NA, Dev RS, Kiran K, Smita N. Behavior and pharmacological animal models for the evaluation of learning and memory condition. Indo Global J Pharm Sci.
2012;2(2):121-9

18. Pattewar, Katedeshmukh RG, Vyawahare NS. Phytomedicines and cognition Int J Pharm Sci and Res. 2011;2(4):778-91.

19. Gireesh KS, Sudhir KC, Geeta R, Shyam SC, Vikas K. Potential antianxiety activity of Fumaria Indica: A preclinical study. Pharmacogn Mag. 2013;9(33):14-22.

20. Ahlemeyer B, Krieglstein J. Neuroprotective effects of Ginkgo biloba extract. Cell Mol Life Sci. 2003;60(9):1779-92.

21. Kim YO, Leem K, Park J, Lee P, Ahn DK, Lee BC, et al. Cytoprotectively effect of Scutellaria baicalensis in CA1 hippocampal neurons of rats after global cerebral ischemia. J Ethnopharmacology. 2001;77(2):183-8.

22. Parle M, Dhingra D, Kulkarni SK. Neurochemical basis of learning and memory. Indian J Pharm Sci. 2004;66(4):371-6.

23. Baddeley AD. Working Memory. Science. 1992;255(5044):556-9.

24. Vogel HG, Vogel WH. Drug discovery and evaluation: Pharmacological assays 2nd Edition, Springer Ver Lag Berlin Heidelberg, New York. 2002,pp.435-6.

25. Cryan JF, Lucki I. Antidepressant like behavioral effects mediated by 5 -Hydroxy tryptamine 2c Receptors. J. Pharmakon Exper Ther. 2000;295(3):1120-6.

26. Pan Y, Wang FM, Qiang LQ, Zhang DM, Kong LD. Icariin attenuates chronic mild stress-induced dysregulation of the LHPA Stress circuit in rats. Psycho neuroendocri. 2010;35(2):272-83.

27. Hritcu L, Cioanca O, Hancianu M. Effects of lavender oil inhalation on improving scopolamine-induced spatial memory impairment in laboratory rats. Phytomedicine. 2012; 19(6):529-34.

28. Mizuno M, Yamada K, Olariu A, Nawa H, Nabeshima T. Involvement of brainderived neurotrophic factor in spatial memory formation and maintenance in a radial arm maze test in rats. J Neurosci. 2000;20(18):7116-21.

29. Titus ADJ, Shankaranarayana BS, Harsha HN, Ramkumar K, Srikumar BN Singh SB, et al. Hypobaric hypoxia-induced dendritic atrophy of hippocampal neurons is associated with cognitive impairment in adult rats. Neuroscience. 2007; 145(1):265-78.

30. Sameshima H, Ikenoue T. Hypoxic ischemic neonatal encephalopathy: animal experiments for neuroprotective therapies. Stroke Res Treat. 2013;2013:1-11.

31. Carranza C, Juárez E, Torres M, Ellner J, Sada E, Schwander S. Mycobacterium tuberculosis growth control by lung macrophages and CD8 Cells from patient contacts. Am J Resp Crit Care Medicine. 2006;173(2):238-45.

\section{GRAPHICAL ABSTRACT}

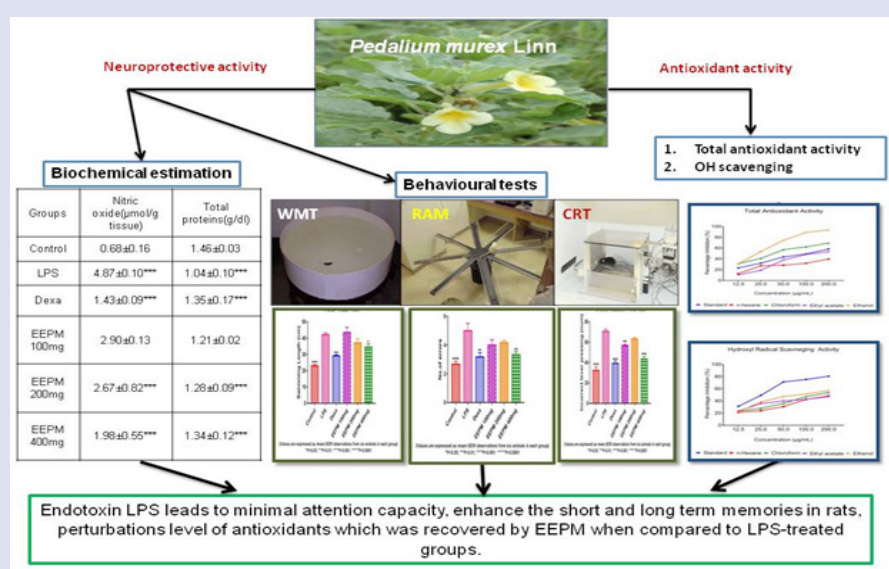

\section{SUMMARY}

- Attention and short-term working memory of the animals was severely impaired by LPS

- The effect of EEPM was assessed by battery of behavioural tests (CRT, RAM and WMT).

- EEPM at $400 \mathrm{mg} / \mathrm{kg}$ significantly improved the LPS induced endotoxemia

- The effect of EEPM may be attributed to the presence of potent antioxidants in $P$. murex leaves.

- Our results showed that EEPM is a hopeful aspirant for hindrance of infection and inflammation induced brain damage by LPS

\section{ABOUT AUTHORS}

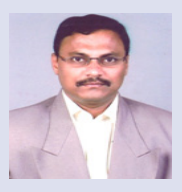

Dr. R. Shanmuga Sundaram, has two decades of experience in teaching profession. Currently he is positioned as Professor and Vice Principal at, JKK Nattraja College of Pharmacy, Komarapalayam. He has done an extensive research work in the field of Neuropharmacology.

Cite this article: Gomathi S, Sundaram RS, Annapandian VM, Vijayabaskaran M. Neuroprotective Effect of Pedalium murex Linn Leaf against Lipopolysaccharide Induced Behavioural Disorders in Rats. Pharmacog J. 2017;9(6):957-62. 